\title{
Teacher's feedback and student's preferences in an Advanced Writing Course: A Case Study
}

\author{
Mohammad Aliakbari (Corresponding author) \\ Dept. of English, Ilam University PO Box 516, Ilam 69315, Iran \\ E-mail:maliakbari@hotmail.com \\ Hossein Raeesi \\ Dept. of English, Ilam University PO Box 516, Ilam 69315, Iran \\ E-mail: raeesi.hossein@gmail.com
}

\author{
Doi:10.7575/aiac.alls.v.5n.1p.62 \\ URL: http://dx.doi.org/10.7575/aiac.alls.v.5n.1p.62
}

Received: 02/01/2014

Accepted: 28/02/2014

\begin{abstract}
This paper was intended to examine teacher's corrective feedback and student's preferences in an advanced writing course. The study was conducted using a questionnaire as the instrument and 15 MA TEFL students from Ilam state university in Iran as the participants. The students were asked to prioritize among a list of ten aspects of error correction and feedback. The findings made it clear that a high majority of the students chose to be corrected, commented, and guided on the issue of organization as their first priority. The results further specified that instructors should realize that advanced students do not like to be treated in the same way as the elementary and intermediate pupils do. Otherwise, it may result in students' discontent and boredom in educational setting.
\end{abstract}

Keywords: Teacher's corrective feedback, Student's preferences, Advanced writing, MA TEFL students

\section{Introduction}

Matching the expectations of teachers and students is of high importance for successful language learning. According to Nunan (1995), "teachers should find out what their students think and feel about what and how they want to learn". If students' and teachers' perceptions of instructional effectiveness do not match, it can lead to students' discontent, thus impairing learning (Brown, 2009; Schulz, 2001). As a result, discovering students' preferences and beliefs toward instructional practices will benefit teachers. Although most research in this area deal with elementary levels, this study investigates MA students' preferences in an advanced writing course.

\section{Literature Review}

Many researchers have underscored the importance of the matching of teachers' and students' expectations for successful learning (e.g., Schulz, 2001; Horwitz, 1988; Nunan, 1987). Meanwhile, mismatches between teachers' pedagogical practices and learners' learning preferences were found in many studies (e.g., Hawkey, 2006; Schulz, 2001; Peacock, 2001; McCargar, 1993; Oladejo, 1993; Cathcart \& Olsen, 1976). Many researchers reported unsatisfactory learning outcomes when there is a mismatch between teacher and student perceptions about the effectiveness of instructional practices (e.g., Schulz, 2001; Green \& Oxford, 1995; Horwitz, 1988; Nunan, 1987). Several researchers have proposed an agreement between teachers' and students' expectations in order for feedback to be effective in writing skills (e.g., Plonsky \& Mills, 2006; Diab, 2005; Jeon \& Kang, 2005; Schulz, 2001; Hyland, 1998; Saito, 1994; Leki, 1991; Raimes, 1991).

In their study regarding EFL and ESL college students' preferences for receiving feedback on certain writing aspects, Hedgecock and Lefkowitz (1994) found that EFL college students prefer and value teacher feedback and corrections on grammatical, lexical, and surface-level features more than those on content and style, whereas ESL students prefer feedback on content to feedback on form.

Kern (1995) compared foreign language students' beliefs about language learning with those of their teachers. He found that students held beliefs about pronunciation, error correction, and the importance of learning grammar and vocabulary that were different from their instructors'.

According to Schulz (2001), students may have widely differing views from teachers regarding how errors should be corrected in the classroom. Some studies have strongly revealed that a difference in beliefs can result in students' frustration and demotivation (e.g., Dornyei, 2003; Sakui \& Gales, 1999).

\section{Statement of the problem}

Iranian MA TEFL students are required to pass a two-credit course on advanced writing. This course is intended, among other things, to teach students how to write an academic paper or article. It is often observed that students make mistakes in their writing and instructors are often unaware of students' preferences to correction. Knowing their 
preferences toward correction, no doubt, can enable instructors to focus on highly desired aspects, allocating as much class time as possible to it.

Teachers' corrective feedback and students' preferences in writing courses have been the focus of extensive research. While the majority of studies in this area have examined students' preferences in elementary and intermediate levels, less work has been done in advanced levels. Accordingly, this study aims to gain a deeper insight into MA TEFL students' preferences to corrective feedback in an advanced writing course in Ilam state university in Iran.

\subsection{Research question}

What aspects of writing do students prefer to be corrected in an advanced writing course?

\section{Method}

\subsection{Participants}

All 15 MA TEFL students of a class in Ilam University were chosen. Of this number of students, there were 9 females and 6 males and the age were above 24. Students majored in different fields of study at their BA program. 10 had a BA in English literature, 4 had a BA in translation, and 1 had a BA in TEFL.

\subsection{Instrument}

In this study a questionnaire which was an adaptation of a similar work done in the area of corrective feedback at the elementary level was employed. To apply it to the participants in question, however, the authors had to add some more advanced error correction options to it. A copy of the questionnaire is appended to the end of paper. It consisted of 3 parts. The first part included some instructions on how the participants should respond to the questionnaire. The second part consisted of ten aspects of error correction arranged on a random basis. And finally the third part had ten blank spaces for the participants to put a number from 1 to 10 based on descending priorities. In order to assess the reliability of the study, test-retest method was employed. The re-test was carried out using ten percent of the students. It was found to be quite high reliable. With respect to validity of the content, it should be noted that these aspects are mainly based on the most widely used types of error corrections which occur in an advanced writing course. Besides, the list has been prepared based on the contents which are often covered in such a course and which already approved by the subjectarea experts.

\subsection{Procedure}

The questionnaires were distributed among all 15 MA TEFL students from Ilam state university in the spring academic term in May 2012 and then they were asked to return it within two days. They were also provided with explanations on how to fill the questionnaire. The data of the questionnaires were then typed into SPSS program and the percentage frequencies were then calculated.

\section{Results}

This section includes the results of the study. The results are shown in the following Table1. The rows show the ten aspects of error correction and the columns show the priorities in a descending order. The table is followed by the discussion.

Table 1. Priorities and percentage frequencies for each aspect of error correction as desired by students in and advanced writing course

\begin{tabular}{lccccccccccc}
\hline & P1 & P2 & P3 & P4 & P5 & P6 & P7 & P8 & P9 & P10 \\
\hline Syntax and Grammar & 13.33 & 6.66 & 13.33 & 0 & 0 & 13.33 & 6.66 & 20 & 26.66 & 6.66 \\
Punctuation and spelling & 0 & 0 & 0 & 0 & 6.66 & 0 & 13.33 & 6.66 & 33.3 & 40 \\
Word choice & 0 & 13.33 & 13.33 & 6.66 & 13.33 & 40 & 13.33 & 0 & 0 & 0 \\
Transition words & 0 & 6.66 & 0 & 6.66 & 0 & 0 & 40 & 33.3 & 13.33 & 0 \\
Structure and organization & 66.66 & 6.66 & 0 & 13.33 & 0 & 6.66 & 13.33 & 0 & 0 & 0 \\
Thesis statement and blueprint & 6.66 & 46.66 & 13.33 & 20 & 6.66 & 6.66 & 0 & 0 & 0 & 0 \\
Coherence and cohesion & 6.66 & 13.33 & 26.66 & 13.33 & 33.33 & 0 & 0 & 0 & 6.66 & 0 \\
Contrastive analysis & 0 & 0 & 0 & 6.66 & 6.66 & 13.33 & 6.66 & 20 & 13.33 & 26.66 \\
Ideas expressed & 0 & 6.66 & 20 & 6.66 & 20 & 6.66 & 0 & 20 & 6.66 & 13.33 \\
Writing style & 6.66 & 0 & 0 & 26.66 & 13.33 & 13.33 & 6.66 & 0 & 0 & 13.33 \\
\hline
\end{tabular}

\subsection{Discussion}

According to the table, 66.66 percent of the students wished to receive comments on the organization of a paper including how to write introduction, body, conclusion, support, etc. This noticeable figure highlighted the importance of organization as the highest priority for this group of MA students. In an advanced writing course the focus is on how to begin, continue, and end a paper. 
The second high priority, according to the table, has to do with thesis statement and blueprint in writing. 46.66 percent of the participants chose to be commented on this aspect. This is also an advanced issue in writing an academic paper. It seems that almost half of the students have problems with this aspect, expecting the instructor to remedy this important dimension of writing.

It seems that the students do not agree on the next three high priorities. This is implied by their dispersed opinions. No absolute choices can be observed for the aspects in question. The third high priority, according to the table, with 26.66 percent deals with text coherence and cohesion. This aspect along with the next two aspects falls between advanced issues and elementary ones. Interestingly, this aspect scored 33.33 percent for the fifth high priority. Generally, aspects regarding text coherence and writing style have been chosen as intermediate priorities.

The table also shows that 40 percent of the students chose to be corrected on word choice as their sixth priority. Word choice aspect is almost near elementary and intermediate levels. Interestingly, this aspect, as a whole, falls in the midst of the priorities.

The seventh and eighth priorities which have been chosen by a low majority of students are concerned with transition words. 40 percent of the students chose it as the seventh priority and 33.3 percent of the students chose it as the eighth priority. This item is also near elementary levels.

And finally 40 percent of the students chose syntax and grammar as the least important priority. These surface-level errors are most often treated in the very beginning stages of writing, so it is natural for advanced level students not to wish to be corrected for these trivial things. It is inferred that content rather than form is of high importance to advanced level students.

\section{Conclusion}

This case study concerning teacher's corrective feedback and student's priorities was conducted in the Ilam state university in Iran. A questionnaire comprising a list of ten aspects of error correction was used and 15 MA TEFL students as the participants were asked to prioritize.

The findings showed that students preferred to be mostly corrected, commented, and guided with organizing a paper. The results also showed that issues such as correcting punctuation, spelling and grammatical errors had the least preferences. Other issues such as text coherence, transition words, etc. lied in the middle of preferences.

In light of the findings, it was inferred that knowing the students' preferences toward correction will enable instructors to focus their energies on aspects on which most students agree and expect to be responded. Put another way, the matching of instructors' and students' expectations will result in the class time being spent effectively only for things which are highly demanded by students rather than for what the instructor thinks are necessary. Moreover, it was inferred that advanced students would not like to be behaved like the elementary ones. This would result in students' boredom and discontent.

In conclusion, it has to be stated that due to the limited number of the participants involved, the results cannot be generalized to other situations. Consequently, this paper recommends that further study be conducted using a larger number of participants and more academic institutes.

\section{References}

Brown. A. (2009). Students' and teachers' perceptions of effective foreign language teaching: A comparison of ideals. Modern Language Journal, 93, 46-60.

Cathcart, R. L., \& Olsen, J. E. W. B. (1976). Teachers' and students' preferences for error correction of classroom conversation errors. In J. F. Fanselow and R. H. Crymes (Eds.), On TESOL '76: Selections based on teaching done at the 10th annual TESOL convention (pp. 41-53). Washington: TESOL.

Cohen, A. D., \& Cavalcanti, M. C. (1990). Feedback on compositions: Teacher and student verbal reports. In B. Kroll (Ed.), Second language writing: Research insights for the classroom (pp. 155-177). Cambridge: Cambridge University Press.

Diab, R. L. (2005). Teachers' and students' beliefs about responding to ESL writing: A case study. TESL Canada Journal, 23, 28-43.

Hedgcock, J., \& Lefkowitz, N. (1994). Feedback on feedback: Assessing learning receptivity to teacher response in L2 composing. Journal of Second Language Writing, 3, 141-163.

Leki, I. (1991). The preferences of ESL students for error correction in college level writing classes. Foreign Language Annals, 24, 203-218.

Nunan, D. (1987). Communicative language teaching: The learner's view. In K. D. Bikram (Ed.), Communication and learning in the classroom community, (pp. 176-190). Singapore: SEAMEO Regional Language Centre.

Nunan, D. (1995). Closing the gap between learning and instruction. TESOL Quarterly, 29(1), 133-158.

Schulz, R. A. (2001). Cultural differences in student and teacher perceptions concerning the role of grammar instruction and corrective feedback: USA-Columbia. Modern Language Journal, 85,244-258. 